\title{
Physicians not immune to intimate partner violence
}

\author{
n Cite as: CMAJ 2018 November 19;190:E1372-3. doi: 10.1503/cmaj.109-5667
}

Posted on cmajnews.com on Nov. 1, 2018.

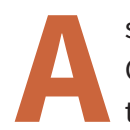
s the date looms for the trial of a Canadian physician accused in the murder of his physician wife, doctors are asking how they can prevent this type of tragedy among their colleagues. According to recent research, an all-too-high proportion of physicians experience violence at the hands of spouses or dating partners.

Toronto neurosurgeon Dr. Mohammed Shamji is scheduled to stand trial in April 2019 for the murder of Dr. Elana Fric-Shamji in November 2016. "It was an extremely painful time for the profession. All of us became introspective about the issue," said Dr. Sohail Gandhi, a family physician in Stayner, Ontario, who wrote about Fric-Shamji's death in the Huffington Post.
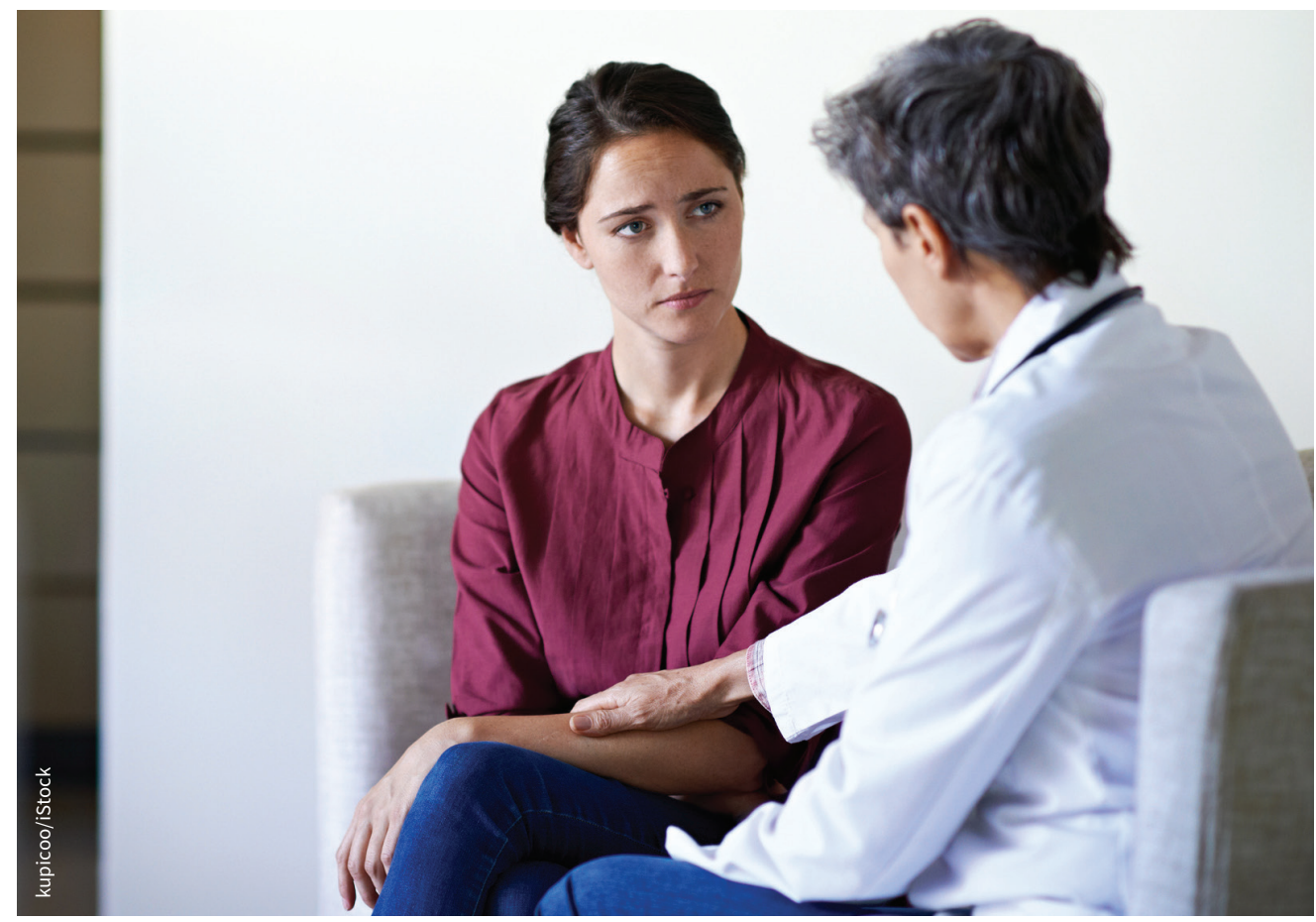

Doctors screen patients for intimate partner violence but may fail to recognize the problem in their own lives.
This is not an isolated incident. An Australian study released this year found that 1 in 10 female health professionals in a large maternity hospital had experienced abuse by a partner in the previous year, a rate higher than in similar studies of women in other occupations in Australia. The study didn't break down results by specific health professions, but about $45 \%$ of physicians surveyed reported intimate partner violence (IPV) or other family violence during their lifetimes.

In other studies, rates of IPV experienced by physicians ranged from $7 \%$ to $24 \%$ for women physicians and from $6 \%$ to $10 \%$ for men, according to a 2016 review of research coauthored by Barbara Hernandez, director of phys- ician vitality at Loma Linda University in California. She has a new study of IPV in US physicians expected to be published soon.

In Canada, $4 \%$ of people older than 15 have experienced physical or sexual violence by a current or former spouse or dating partner in the past 5 years, according to Statistics Canada's General Social Survey (2014 data). About $80 \%$ of victims reporting to police are women. There are no breakdowns or studies by occupational group.

Physicians are "certainly not" immune to IPV, said Hernandez, but they may be less likely than other victims to report it.

After the death of US physician Dr. Casey Drawert in a domestic violence incident in March 2016, Dr. Esther Choo wrote, "Where does an admission of an abusive relationship fit into the narrative of the successful and intelligent woman, especially in a cohort that is self-critical and high-achieving?" in a blog post on FeminEM, a website for women in emergency medicine.

According to Hernandez, "Physicians are trained to screen their patients for IPV, but few consider that they themselves could find themselves in such a relationship. There's considerable stigma around it. The attitude is, 'You're so smart, you should have known better."'

The options for leaving an abusive relationship also pose barriers for physicians. "One of the questions I've 
heard is, 'Where am I supposed to go?'” said Hernandez. Shelters for abused women may be located in marginalized neighbourhoods. Physicians going there might be worried about encountering their patients. In a survey of physicians Hernandez conducted recently, the most common response to what to advise a physician-patient suffering abuse was, "Send them to a shelter." Yet respondents said sending physicians to a shelter was also the least feasible and desirable option.

Fleeing on their own also has a downside. Abused women need support, counselling and often basic necessities, said Hernandez. Some abusers control the couple's finances, and their victims "might have all the trappings of a successful life but not have money."

Gandhi believes physicians can help their colleagues in ways similar to how they help patients. He has advocated for regular physician screening of abuse among patients in an interview with CBC Radio's The Current. In his practice, Dr. Gandhi's software reminds him to ask patients, "Do you feel safe at home?" This simple step has uncovered several patients affected by abuse, he said.

But many Canadian physicians don't have their own physician. As presidentelect of the Ontario Medical Association,
Gandhi said the association is trying to change that. "When you have a familiarity and ongoing relationship, especially a patient-physician relationship, it does make it easier to disclose what's going on in your personal life."

The first step is to talk openly about IPV. "If you go to a physician conference, you will never hear a presentation on this topic," said Hernandez. According to Gandhi, "The more people start talking about it, the more it becomes acceptable to talk about what is going on. I'm hopeful that we can bring it out into the open."

Carolyn Brown, Ottawa, Ont. 